\title{
VIOLÊNCIA E FAMÍLIA: POSSIBILIDADES VINCULATIVAS E FORMAS DE SUBJETIVAÇÃO
}

\author{
VIOLENCE AND FAMILY: BINDING POSSIBILITIES \\ AND FORMS OF SUBJECTIVITY \\ LA VIOLENCIA Y LA FAMILIA: POSIBILIDADES \\ DE ENLACE Y FORMAS DE SUBJETIVIDAD \\ Anamaria Silva Neves* \\ Layla Raquel Silva Gomes** \\ Lorena Candelori Vidal***
}

\section{Resumo}

Este artigo apresenta estudos realizados a partir do atendimento psicoterápico de base psicanalítica à mãe e à filha de uma família que têm a violência como principal elemento articulador de sua história. O homem contemporâneo, em sua busca incessante pela felicidade, vê-se impossibilitado de ter assegurada a satisfação plena de seus desejos, instalando um paradoxo. Essa análise possibilitou um olhar diferenciado sobre o sujeito contemporâneo e as estratégias deste para lidar com a questão do desamparo. A família apresentada ilustra como o vínculo se estabelece e se mantém através de um acordo inconsciente imposto ou mutuamente concluído. Trata-se de um conluio que possibilita a continuidade dos investimentos e dos benefícios ligados à subsistência do contrato narcísico. Os sujeitos, imbuídos da relação violenta, retratam que, ao tentar escapar do enfrentamento da violência fundamental, se lançam ao desamparo. Deste modo resta-lhes a destruição do outro como alternativa para afirmação da singularidade e alívio de sua tensão pulsional.

Palavras-chave: violência; vínculo; subjetivação.

\footnotetext{
* Universidade Federal de Uberlândia, Uberlândia, MG, Brasil.

** Universidade Federal de Uberlândia, Uberlândia, MG, Brasil.

*** Universidade Federal de Uberlândia, Uberlândia, MG, Brasil.
} 


\section{Abstract}

This article presents achieved studies from a family's psychoanalytic psychotherapy whose main articulator element of its history is the violence. Modern man, in his relentless pursuit of happiness, finds himself unable to be assured of full satisfaction of their desires, installing a paradox. This analysis allowed to discover a different point of view about the contemporary subject and his strategies for dealing with this helplessness issue. The family presented in this study illustrates the way how the link is established and maintained through an unconscious agreement, which is imposed or mutually concluded. It is a collusion that enables continued investments and benefits related to subsistence of the narcissistic contract. Subjects, which are imbued with the violent relationship, portray that the subject is cast helpless to try to avoid facing the fundamental violence. That implies to the subject try to destroy the other as the alternative to assert their own singularity and relieving their pulsional tensions.

Keywords: violence; bond; subjectivity.

\section{RESUMEN}

Este trabajo presenta los estudios realizados a partir de terapia psicoanalítica para una madre y su hija de una familia que tiene la violencia como elemento articulador principal de su historia. El hombre moderno, en su incesante búsqueda de la felicidad, se ve incapaz de haber asegurado la plena satisfacción de sus deseos, instalando una paradoja. Este análisis permitió una visión diferenciada del sujeto contemporáneo y sus estrategias para hacer frente a la cuestión del desamparo. Esta familia ilustra cómo se establece y se mantiene el vinculo mediante un acuerdo inconsciente que se le impuso o mutuamente finalizado. Este es un truco que permite la continuación de las inversiones y los beneficios relacionados con la subsistencia del contrato narcisista. Los sujetos, imbuidos de la relación violenta, retratan que al intentar hacer frente a esta violencia fundamental, se lanzan el desamparo. De este modo, sigue siendo para ellos la destrucción del otro como alternativa para hacer valer la singularidad y el alivio de su tensión pulsional.

Palabras clave: violencia; enlace; subjetividad.

\section{Introdução}

Este artigo articula alguns estudos que puderam ser realizados a partir do atendimento psicoterápico de base psicanalítica a uma família que tem a violência 
como principal elemento articulador de sua história. Como fundamento teórico, emerge a Psicanálise, espaço profícuo e dinâmico do saber, configurando instrumento de manejo clínico e reflexivo na busca de subsídios para a compreensão do fenômeno da violência. Em específico, ampara-se na Psicanálise freudiana e na perspectiva vincular de modo a compreender a dinâmica que se estabelece no caso clínico eleito a partir de uma investigação dos vínculos que sustentam a subjetivação dos sujeitos.

A contemporaneidade expóe o homem ao absurdo de sua constituição. Em sua busca incessante pela felicidade, o homem vê-se impossibilitado de ter assegurada a satisfação plena de todos seus desejos. Em "O mal-estar na civilização”, Freud (1930/1980) debruça-se sobre a questão e pontua que a satisfação do instinto equivale para os homens à felicidade, derivando disso um grande sofrimento. Afinal, o mundo externo pode recusar-lhe tal satisfaçáo e a tarefa de evitar o sofrimento coloca, então, a luta pela obtenção do prazer em segundo plano.

O processo civilizatório é marcado pela renúncia e pelo sentimento de insatisfação que os homens experimentam ao viver em sociedade. Dessa insatisfação resulta o mal-estar na civilização, produzido pelo conflito irreconciliável entre as exigências pulsionais e as restriçôes civilizatórias. Quando a energia investida pelo ego - em busca de satisfação de seus desejos - encontra a interdição do mundo externo, esta é reinvestida na busca de medidas paliativas e construçóes auxiliares (Freud, 1930/1980). Assim, este artigo busca apresentar, a partir de um caso clínico, como a violência pode estar associada a uma tentativa do sujeito de resolver seus conflitos e satisfazer suas pulsóes individuais e sociais, especialmente em relação ao imperativo da constituição do laço social. Segundo Ceccarelli (2009), no decorrer da vida os sujeitos reagem às situaçôes de desamparo segundo o protótipo construído na infância, isto é, em construçóes imaginárias simbólicas, que podem ser compostas por laços sociais oferecidos pelo mundo externo em determinada cultura e momento histórico. Pretende-se estabelecer, com isso, balizas que possibilitem relacionar a violência como tentativa de inclusão/manutenção no laço social, tomando como esteio a contemporaneidade.

\section{O Sujeito e a Contemporaneidade: desamparo e existência subjetiva}

A fim de compreender o fenômeno da violência no contexto contemporâneo, faz-se necessário elucidar de que forma esse tempo histórico se caracteriza, especialmente no que diz respeito às normas que regulam as relaçóes entre os 
membros da sociedade. Ponto fundamental a se destacar sobre a contemporaneidade é a predominância dos valores regidos por uma lógica narcísica que escamoteia o outro para a posição de objeto de realização de desejo e satisfaçáo individual (Piva, Severo, \& Dariano, 2007).

Marin (2001) discute a respeito do paradoxo que se estabelece nos dias atuais no qual estão presentes a negaçáo do sofrimento e a luta incessante pela felicidade. $\mathrm{O}$ paradoxo se instala na constatação de que, embora seja central a satisfação plena dos desejos individuais, a sociedade está marcada pelo desamparo, uma vez que o sujeito se depara constantemente com o fim das ilusóes e utopias e se vê à mercê de si mesmo.

Cavalcante e Pinheiro (2009) compreendem como princípio regulador da sociabilidade na contemporaneidade a insatisfação e a consequente busca desenfreada pela satisfação. Afirmam que, desse modo, o vínculo social funciona como meio pelo qual o sujeito adquire seus objetos de desejo. A civilização, portanto, é fundada no recalque pulsional, sendo o mal-estar e o sofrimento humano consequências das interdiçóes excessivas dos desejos de ordem sexual.

Sobre este aspecto, Marin (2001, p. 10) aponta que "a necessidade de renunciar à completa satisfação dessas pulsóes, para preservar a singularidade e a presença inexorável do outro que determina a existência de cada um, é o paradoxo da constituição do sujeito e do social". Para lidar com o paradoxo entre a constituição do sujeito e do laço social, o sujeito precisa encontrar formas de expressão e realização pulsionais que se adéquem aos ditames culturais. A forma mais comum e singular que o sujeito encontra é por meio da produção do sintoma. Sendo assim, com a análise do sintoma é possível compreender a relaçâo que se estabelece entre a organização social e cultural e as tentativas de realização pulsional do sujeito (Marin, 2001).

Para garantir a existência subjetiva, além de produzir o sintoma o sujeito pode se submeter ao poder de uma categoria na qual busca reconhecimento. De acordo com Peixoto Jr. (2004, p. 2) "a subjetividade procura o signo de sua existência fora de si mesma, num discurso ao mesmo tempo dominante e indiferente", de modo que, na impossibilidade de realização plena dos desejos, o sujeito tende a perseguir a subordinação como promessa de existência a ser atribuída por um outro diante do qual se sente vulnerável. Submetido ao outro para se subjetivar, o sujeito se vê compelido a repetir suas normas, uma vez que a ausência da repetição coloca em risco a sua existência.

Peixoto Jr. (2004) proporciona elementos que nos ajudam a compreender a questão da subjetivação, apresentando os novos processos de produção de subjetivação que surgem com a contemporaneidade à medida que o sujeito se vê diante 
do desamparo que o constitui. As exigências contemporâneas que inserem o sujeito em uma constante batalha contra o reconhecimento da dor e do sofrimento o impelem a buscar sua existência e se diferenciar. Assim, ele pode encontrar na violência uma possibilidade de subjetivação. Desse modo, a violência como forma de subjetivação é uma proposta interpretativa que este artigo elege para a compreensão da violência intrafamiliar por meio da análise de um caso clínico.

\section{Violência: marco da intersubjetividade}

A retomada histórica pelo crivo psicanalítico apresenta a violência exercendo importante função no fundamento da cultura e do social no processo civilizatório. Freud (1913/1974c) teoriza que na sociedade totêmica o aspecto social se expressa principalmente por uma ordem mantida através da força e de amplas restriçôes. Os membros do clá totêmico estavam submetidos ao totem, o qual eram proibidos de matar. Neste contexto, todos os membros eram considerados irmãos e irmãs e eram moralmente obrigados a ajudar e proteger uns aos outros.

Na matriz do processo civilizatório, o pai detinha o domínio e o controle, instaurando a primazia do mais forte sobre os mais fracos. Movidos por sentimentos ambivalentes os filhos se unem a fim de executar o assassinato do pai, fato que provoca em mesma medida sentimentos ambivalentes que fazem sucumbir ao pai, um lugar simbólico primordial. A organização social funda-se, portanto, na e pela renúncia à satisfação pulsional, através da criação de tabus ao parricídio e ao incesto pelo reconhecimento de obrigaçóes mútuas e pela institucionalização da moralidade e da lei (Cavalcante \& Pinheiro, 2009).

Nessa perspectiva, a imposição da violência na ordem cultural, tanto pela dominação dos filhos pelo pai forte, quanto pela união dos filhos fracos contra a força superior do pai, ou ainda, pelo parricídio ou rivalidade entre os irmãos, se configuram como tentativa de reprimir qualquer força adversária. Marin (2001) conclui que o ato violento destrutivo é a forma que o indivíduo submetido a forças pulsionais intensas encontra para afirmar sua singularidade, eliminando o outro que lhe é fonte de sofrimento.

Piva et al. (2007) distinguem a violência em dois sentidos pulsionais: como destruição e signo de morte e como uma força de vida que leva à produção da criatividade (agressividade). Em consonância com o primeiro sentido, a violência pode ser compreendia como anterior à lei e inerente ao homem, sendo gerada a partir da existência do outro diferente, isto é, no marco da intersubjetividade. Retomando a questão do desamparo na contemporaneidade, oriundo da ferida 
narcísica representada pela impossibilidade de realização plena em função do processo civilizatório a partir da presença do outro, tem-se que este outro representa fonte de sofrimento e a violência pode servir para eliminar o mal-estar.

Cavalcante e Pinheiro (2009, p. 9) afirmam que, desta maneira,

a manutençáo do laço social acontece no sentido de barrar a constante ameaça de desintegraçáo civilizatória operada pelo exercício paralelo e ambivalente humano da sexualidade e da agressividade, ou ainda, pela luta constante entre a pulsão de vida e a pulsão de morte.

A violência, por este viés, pode ser compreendida como possibilidade vinculativa, uma vez que para existir é fundamental a presença do outro e se institui na medida em que ambos se fazem sujeitos em uma relação, marcada pela imposição do poder. Esta é então definida como investimento de força e agressividade direcionado a resolução dos conflitos e à satisfação das necessidades do sujeito, principalmente no que se refere ao seu pertencimento, ao laço social. Infringir violência a um outro que lhe é semelhante pode se configurar uma estratégia de asseguramento das características exigidas pela cultura e socialmente valorizadas, formando o sentimento identitário do sujeito.

\section{Caso clínico: arranjo familiar, violência e subjetivaçáo}

A família apresenta distintas versões e arranjos, nas várias culturas e períodos históricos. Mesmo não comportando uma definição unívoca, a família "é um grupo primordial no âmbito do desenvolvimento de sujeitos psíquicos singulares" (Neves, 2009, p. 34). Enquanto instituição primária, é um espaço fundamental ao desenvolvimento de seus membros.

Elege-se neste trabalho realizar a leitura de um caso clínico de uma família representada por mãe e filha, atendidas individualmente por psicoterapeutas distintas, durante aproximadamente 10 meses, em sessóes semanais. Mãe e filha chegam ao serviço de psicoterapia de base analítica através do encaminhamento de uma pesquisadora que havia realizado entrevistas para uma dissertação de Mestrado, por meio das quais identificou a demanda de atendimento para ambas. Os nomes que se seguem são fictícios a fim de resguardar a identidade dos envolvidos.

A história da família de Hélio e Maria, a ser apresentada, revela personagens contemporâneos que possibilitam, em seu enlace afetivo, reflexão acerca de 
como essa família se constitui na e pela violência. Hélio e Maria se conheceram muito jovens e o enlace amoroso não tardou a se concretizar com a gravidez de Maria, aos 13 anos de idade. "Além da barriga, crescia também o sonho de construir uma família”, como disse Maria, sinalizando a possibilidade de pertencer novamente a um lugar. Maria perdeu a mãe aos nove anos de idade e poucos dias depois o pai colocou os filhos para fora de casa. Estes foram morar com um irmão mais velho e começaram a trabalhar para que assumissem suas vidas fora dali, conforme a esposa do irmão insistia em dizer. Seduzida pelas promessas de Hélio, os dois passaram a morar juntos.

Além de Irene, primeira filha do casal, a família foi se constituindo com mais três filhos: Daniel, João e Clarisse. A partir de então, o casamento idealizado por Maria é sabotado pela própria conjunção familiar ensaiada e o dia-a-dia foi revelando uma face perversa de estarem juntos. Hélio começa a fazer uso abusivo de bebidas alcoólicas. Maria passa a desconfiar de traiçóes do marido e, quando estas eram descobertas e delatadas, Maria era agredida com socos e pontapés por Hélio.

Maria conta que a gravidez dos quatro filhos foi perpassada por conflitos. Algumas marcadas pela violência física das brigas com Hélio, outras pelo abandono que a obrigava trabalhar para ajudar a manter o sustento da casa, inclusive até dois dias antes de dar à luz. Após o nascimento das crianças e a separação do casal, os filhos ficavam pouco tempo com os pais em virtude do trabalho e dos vícios, e as condiçôes que tinham para se desenvolverem também foram delegadas a parentes, vizinhos e a eles próprios.

As violências físicas, verbais e psicológicas tornaram-se uma constante na família e resultaram na separação do casal após sete anos de relacionamento. Mesmo depois de declarada a separação, Hélio perseguia Maria e os filhos, protagonizando novas, porém não inéditas, cenas de violência na tentativa de impedir o afastamento. Atuação e manipulação para manterem-se juntos, a qualquer custo, para satisfazer o que é da ordem do desejo.

Após a separação, Maria dedicou-se ao sustento das quatro crianças trabalhando em lares como doméstica e complementando a renda com a prostituição. Como passava muito tempo fora de casa, a ausência da mãe foi marcante em grande parte da infância das crianças que, à medida que foram crescendo, foram revelando serem importantes fragmentos dessa rede vinculativa original. Apresentava-se aos poucos durante as sessóes uma família de reedições e repetiçóes, que, de acordo com cada cena trazida por mãe e filha aos atendimentos, ia ilustrando como o vínculo foi se estabelecendo e se mantendo através de um acordo inconsciente imposto ou mutuamente concluído. 
Hélio casou-se novamente com outra mulher e com ela também teve filhos. Entretanto, recebia a visita dos filhos mais velhos, com maior frequência de Clarisse e Daniel, este último chegando a morar por algum tempo na casa do pai com a madrasta. Nessas visitas à casa do pai, Clarisse era violentada sexualmente por Hélio. Após a denúncia, enquanto repercutia o caso na rede de atenção às famílias e com histórico de violência sexual, Hélio cometeu suicídio.

Com tal desfecho, mãe e filha passaram a contracenar uma relação conflituosa e violenta. O conflito evidente já estabelecido entre elas durante as entrevistas, nas quais eram sujeitos da pesquisa de mestrado, tornou o atendimento familiar inviável em um primeiro momento, uma vez que, após a morte do pai, elas sequer suportavam viver na mesma casa, com acusaçóes e ataques constantes. Sendo assim, foi idealizado o acompanhamento psicológico com psicoterapeutas distintas e atendimento individual para ambas, na mesma instituição. Com os atendimentos posteriores, os elementos da entrevista iam ajudando a compor o cenário que ia revelando laços afetivos que deflagravam a violência como única forma de manterem-se vinculados enquanto família.

Durante o trabalho analítico, Maria relata que sua infância também foi perpassada pela violência. Quando criança apanhou e viu a mãe apanhar do pai alcoólatra por diversas vezes. $\mathrm{O}$ mundo lhe era restrito, o pai separava inclusive as porçóes que cada um dos filhos poderia comer, torturando-os ao comer na frente deles o que lhes era negado. Sua mãe morreu de um câncer que nunca fora tratado e que ainda trazia à memória de Maria os cuidados que requeria até definhar. Ficava presente nas falas de Maria, desde o início dos atendimentos, algo de uma criança que fora abandonada, imersa em uma realidade difícil de ser assumida, mas que dava indícios de ter sido estranhamente escolhida. Algo que parecia não lhe pertencer, mas que era familiar. Maria era hospedeira de uma história inconsciente que pôde se apresentar através do trabalho analítico.

\section{Reconhecimento da violência fundamental e a possibilidade do resgate do laço social}

A estrutura vincular presente na família representa a matriz básica que constitui o sujeito (Correa, 2003). Sendo assim, o grupo familiar é um espaço privilegiado para transmissão psíquica de laços afetivos que, permeados por aspectos inconscientes, liga os membros da família com o passar do tempo.

Devido a essa herança psíquica, aspectos inconscientes, não elaborados, assumem dimensão transgeracional. A herança psíquica transgeracional advém de 
histórias permeadas por vivências traumáticas, de não ditos e lutos não elaborados que irrompem nos herdeiros, atravessando seu espaço psíquico sem apropriação possível por não terem sido elaborados nem mesmo pelas geraçóes precedentes (Sei \& Gomes, 2007).

Para Kaës (2005), é através de alianças inconscientes que a transmissão da vida psíquica efetua-se entre as geraçóes. Para isso, é imposto ou mutuamente concluído um acordo inconsciente que organiza e mantém o vínculo em sua complementaridade de interesses, a fim de se garantir a continuidade dos investimentos e dos benefícios ligados à subsistência do contrato narcísico: "as alianças inconscientes enodam-se para que os sujeitos de um vínculo estejam assegurados de nada saber sobre seus próprios desejos, nem daqueles que os precederam" (Kaës, 2005, p. 133).

Em busca de um espaço lugar de pertença, Maria encontrou Hélio e com ele reproduziu uma história igualmente familiar, um estranho familiar. Em seu texto "O estranho", Freud (1919/1987) discute que o estranho deriva seu terror não de alguma fonte externa ou desconhecida, mas, pelo contrário, de algo estranhamente familiar que supera quaisquer esforços do indivíduo de se separar dele. Nesse sentido, no trabalho analítico com Maria emergem elementos transgeracionais que implicam no funcionamento psíquico do grupo familiar.

O assujeitamento e a imposição no sentido vincular estão relacionados à afetividade entre os membros do grupo social e às regras que regem os relacionamentos entre eles. Piva et al. (2007) apontam que a função de indicação dos lugares e posiçóes na estrutura de parentesco é fundamental e possibilita o estabelecimento de parâmetros definitórios de cada relação e de todos os vínculos da estrutura familiar. A indicação confere sentido ao contexto familiar, possibilitando a diferenciação do não-familiar, delimitando as funçôes específicas de cada membro e as regras que orientam a relação estabelecida.

Como exposto no caso clínico, Maria e Hélio protagonizam uma formação familiar em que não são claros os lugares simbólicos assumidos por seus membros. A presença da violência incestuosa enfatiza essa questão, uma vez que no cenário familiar estão presentes relaçóes que perpassam o tabu instituído culturalmente, propiciando ensaios de relaçóes não previstas no projeto familiar. Do mesmo modo, a violência, no intermédio das relaçóes entre seus membros - cujos tons afetivos poderiam ser formados pelo companheirismo e o amor -, denota parâmetros afetivos confusos por onde atravessam diferentes possibilidades vinculativas.

A compreensão da estrutura familiar em que a violência comunga como possibilidade vinculativa requer um resgate da história pessoal e familiar do sujei- 
to que permita revisitar as relaçóes primárias que possibilitaram sua constituição psíquica. A esse respeito, Correa (2003) aponta que ao nascer, a criança inscreve-se em registros biológicos, jurídicos e psíquicos. $\mathrm{O}$ processo de filiação, enquanto processo psíquico vincular, se dá por mecanismos e motivos inconscientes que acontecem via transmissão intersubjetiva. Como forma de funcionamento psíquico originado nas primeiras relaçóes objetais, o vínculo estabelece um laço primordial.

A partir das primeiras manifestações do bebê, o meio tentará oferecer respostas à luz do que conhece, valoriza e anseia dentro de cada cultura. Essas interpretações das manifestações são imprescindíveis para a criança, que nasce completamente desamparada, no sentido de não possuir recursos próprios para garantir sua própria sobrevivência (Marin, 2002).

Contudo, como aponta Marin (2002, p. 83), essa manifestação de vida, em busca da satisfação da necessidade, "revela o desequilíbrio, a falta, a perda de um estado desejado de paz e invulnerabilidade, que é considerado violento à medida que aponta para o fracasso do encontro pleno". É esse momento de encontro/desencontro que conceitua a violência fundamental.

A violência fundamental inaugura o contato humano com uma impossibilidade de plenitude, mas paradoxalmente possibilita a criação do novo, que é o surgimento do Eu e do outro. Ou seja, a descoberta do mundo exterior é violenta, mas é o que constitui o indivíduo social. Nesse movimento, o homem é guiado a um trabalho que transforma o registro de uma violência bruta, original, em um motor pulsional que vai cooperar para que representaçóes e afetos possam dar sentido às relaçóes com os outros, tornando aquela violência reflexo de sobrevivência, civilizada e civilizadora para o ser humano (Marty, 1997, citado em Marin, 2002).

Reconhecer a violência como elemento constitutivo da subjetividade permitiu compreender como a família de Hélio e Maria se organiza e se mantém. As irrupçóes destrutivas, que deixam marcas físicas, móveis quebrados, entre outros, são atuaçóes de uma violência direcionada ao outro que representa igual risco para quem as comete. Ao tentar escapar do enfrentamento da violência fundamental, o indivíduo se lança ao desamparo, restando-lhe como alternativa para afirmação da singularidade e alívio de sua tensão pulsional a própria destruição do outro.

Marin (2001) aponta que, ao assumir os afetos violentos e desagradáveis que não possuíam lugar em si na busca narcísica, cria-se, através do aumento da tolerância ao outro, a possibilidade de resgate do laço social. O homem tem no desejo de reconhecimento, a condição de fazer-se humano, ou seja, ele existe por causa de um outro. 
Assim, é possível reconhecer a família de Hélio e Maria como uma trama de arranjo complexo, que deflagra as tentativas de seus membros de se constituírem sujeitos. A trama familiar que representa fonte de satisfação dos desejos, em um primeiro momento, mostra como pode infligir sofrimento. Desse sofrimento, a partir da violência fundamental, Hélio, Maria e os filhos constituem um vínculo, violento em sua estrutura, numa tentativa de reconhecer o outro e, assim, a si próprios.

\section{Consideraçóes finais}

Ao longo deste artigo, a Psicanálise, em uma perspectiva vincular, possibilitou compreender o fenômeno da violência em seu sentido contemporâneo de tentativa de inclusão/manutenção do laço social. Com isso, as tentativas de aproximação à dinâmica familiar de Hélio e Maria puderam ser subsidiadas para que, através de sua unicidade, pudéssemos contribuir com as reflexôes sobre a contemporaneidade. A análise do paradoxo que constitui a contemporaneidade possibilitou lançar um olhar diferenciado sobre sujeito e as estratégias que este exerce para lidar com a questão do desamparo a que está permanentemente exposto.

No doloroso percurso das renúncias pulsionais, o sujeito se vê impelido a buscar formas de expressão e realização pulsional que estejam adequadas às normas e regras instituídas culturalmente. Paradoxalmente, é no encontro com o outro, isto é, no marco da intersubjetividade, que o desamparo se instaura e é também a partir da relação que o sujeito estabelece com o outro que ele lida com essa questão. Em suas diversas possibilidades, o sujeito pode encontrar na relação de poder, tanto na dominação, quanto na subordinação, sua maneira de existir e se subjetivar (Peixoto Jr., 2004).

A violência, desse modo, irrompe como investimento de força e agressividade direcionado à resolução dos conflitos e à satisfação das necessidades do sujeito, principalmente no que se refere ao seu pertencimento ao laço social. Como no caso apresentado, as violências físicas, verbais e psicológicas constantes na família, seguidas pela violência sexual incestuosa e pelo suicídio do pai, marcam uma fragilidade na função de indicação de posições assumidas no cenário familiar e escancaram a violência como organizadora cruel da relação entre os membros.

A história apresentada ilustra de que maneira o vínculo se estabelece e se mantém através de um acordo inconsciente imposto ou mutuamente concluído. Um conluio que possibilita a continuidade dos investimentos e dos benefícios 
ligados à subsistência do contrato narcísico. Os sujeitos, imbuídos da relação violenta, retratam que, ao tentar escapar do enfrentamento da violência fundamental, o sujeito se lança ao desamparo, restando-lhe como alternativa para afirmação da singularidade e alívio de sua tensão pulsional a destruição do outro.

Com os preceitos psicanalíticos, compreende-se o paradoxo e a ambivalência que são constituintes do sujeito. Encontra-se no escopo da Psicanálise o comprometimento com a verdade do sujeito, uma vez que possibilita algumas respostas à busca de sentido que dá contorno à condição humana. $\mathrm{O}$ viés psicanalítico propóe que o homem assuma o pathos como constituinte de sua condição, pois negando a dor, a paixão, a tristeza, a violência o homem também nega a si. Dessa forma, a clínica psicanalítica abre suas portas e convida o homem contemporâneo a ver o absurdo que o constitui, e "se possível, ajudá-lo a reconciliar-se com ele, com o absurdo, e consigo mesmo" (Herrmann, 1984, p. 16).

\section{Referências}

Cavalcante, K. C., \& Pinheiro, C. V. de Q. (2009). Por uma abordagem psicanalítica da violência na contemporaneidade. In: Laboratório sobre as novas formas de inscriçóes do objeto (org.). As intermitências do Poder, da Morte e da Biopolitica Moderna, II Congresso Sul-Americano de Psicanálise sobre Violência, Culpa e Ato: causas e efeitos subjetivos, 2(1), 1-10.

Ceccarelli, P. R. (2009). Laço social: uma ilusão frente ao desamparo. Reverso, 31(58), 33-42.

Correa, O. B. R. (2003). Transmissão psíquica entre gerações. Psicologia USP, 14(3), 35-45.

Freud, S. (1974). Totem e tabu. In S. Freud, Edição standard brasileira das obras psicológicas completas de Sigmund Freud, v. XIII. Rio de Janeiro: Imago. (Trabalho original publicado em 1913)

Freud, S. (1980). O mal-estar na civilização. In S. Freud, Edição standard brasileira das obras psicológicas completas de Sigmund Freud, v. XXI. Rio de Janeiro: Imago. (Trabalho original publicado em 1930)

Freud, S. (1987). O estranho. In S. Freud, Edição standard brasileira das obras psicológicas completas de Sigmund Freud, v. XVII. Rio de Janeiro: Imago. (Trabalho original publicado em 1919)

Herrmann, F. (1984). O que é psicanálise? São Paulo: Brasiliense.

Kaës, R. (2005). Os espaços psíquicos comuns e partilhados - Transmissão e negatividade. São Paulo: Casa do Psicólogo.

Marin, I. S. K. (2001). O sofrimento e a contemporaneidade. Pulsional Revista de Psicanálise, 14(146), 7-14.

Marin, I. S. K. (2002). Violências. São Paulo: Escuta / FAPESP. 
Neves, A. S. (2009). Família no singular, histórias no plural: a violência física de pais e mães contra filhos. Uberlândia: EDUFU.

Peixoto Jr., C. A. (2004). Sujeição e singularidade nos processos de subjetivação. Ágora: Estudos em Teoria Psicanalítica, 7(1), 23-38. Recuperado em 15 setembro, 2012, de <http:// www.scielo.br/scielo.php?script=sci_arttext\&pid=S1516-14982004000100002\&lng=en \&tlng=es. 10.1590/S1516-14982004000100002>.

Piva, Â., Severo, A., \& Dariano, J. (2007). Poder e violência - Formas de subjetivação e desubjetivação. Contemporânea - Psicanálise e Transdisciplinaridade, 2, 63-77. Recuperado em 15 setembro, 2012, de <http://www.revistacontemporanea.org.br/site/wp-content/artigos/ artigo76.pdf>.

Sei, M. B., \& Gomes, I. C. (2007). Violência familiar, o transgeracional e a arteterapia com família. Aproximaçōes, 11, 133-139.

Recebido em 04 de março de 2012 Aceito para publicação em 03 de dezembro de 2012 